\title{
ANÁLISE DOS CUSTOS EM JUDICIALIZAÇÃO DA SAÚDE NA AMAZÔNIA OCIDENTAL, BRASIL
}

\author{
ANALYSIS OF COSTS IN HEALTH JUDICIALIZATION IN THE \\ WESTERN AMAZON, BRAZIL
}

\author{
Francisco Naildo Cardoso Leitão, 2, 3 \\ Daiane Mendes Rodrigues $2,3,4$ \\ Juliana Maria Bello Jastrow ${ }^{2,6}$ \\ Rejane Rosas Barbary de Deus ${ }^{2}$ \\ Ocilma Barros de Quental2, 5 \\ Mauro José de Deus Morais ${ }^{2,3}$
}

RESUMO: Introdução: Há posicionamentos favoráveis e desfavoráveis no que tange a implementação e execução da política pública de saúde por meio de decisões judiciais que impõem a aquisição de serviços em saúde, com possibilidade de comprometer a sistemática da programação da política Pública de Saúde por meio do Sistema Único de Saúde (SUS). Neste contexto, os problemas com a judicialização da saúde é uma importate via de acesso aos serviços em saúde pública, mas pode significar sérios riscos a sistemática e planejamento ao atendimento das necessidades coletivas. Objetivo: Analisar os custos da judicialização da saúde no Estado do Acre, Amazônia Ocidental, Brasil. Método: Estudo transversal descritivo e documental, com dados secundários obtidos no Sistema de Informação Orçamentária Pública em Saúde (SIOPS), Sistema de Administração Orçamentária, Financeira e Contábil (SAFIRA), junto à Secretaria de Estado de Saúde do Acre e por processos judiciais obtidos junto ao sítio eletrônico do Tribunal de Justiça do Estado do Acre (TJ/AC), no período de 2010 a 2016. Resultados: Os custos da judicialização da saúde no Estado do Acre, no período de 2014 a 2017 foram superiores a $R \$ 10,5$ milhões de reais distribuídos entre medicamentos $(53,16 \%)$ e material médico/hospitalar $(0,49 \%)$. Destaque-se para

1. Doutorando em Ciências da Saúde no Centro Universitário FMABC, São Paulo -SP, Brasil.

2. Laboratório Multidisciplinar de Estudos e Escrita Cientifica em Ciências da Saúde, Rio Branco - AC, Brasil.

3. Universidade Federal do Acre (UFAC), Rio Branco - AC, Brasil.

4. Mestranda em Geografia da Universidade Federal do Acre, Rio Branco - AC, Brasil

5. Faculdade Santa Maria, Cajazeira - PB, Brasil.

6. Graduanda em Enfermagem da Escola Superior da Santa Casa de Misericórdia de Vitória, Vitória ES, Brasil.

Autor Correspondente: francisco.leitao@ufac.br. 
uma fragilidade de registros contábeis correspondente a 4,8 milhões de reais $(46,35 \%)$ dos recursos aplicados com judicialização, e representam $0,31 \%$ dos recursos investidos em saúde no mesmo período no Estado do Acre. Conclusão: $O$ custo da judicialização da saúde no Estado do Acre existe e não é devidamente aprovisionado no planejamento orçamentário e financeiro, comprometendo a sistemática de gastos da Política Pública em Saúde.

Palavras-Chave: Políticas de Saúde Pública. Custo em Saúde. Judicialização da Saúde.

ABSTRACT: Introduction: There are favorable and unfavorable positions regarding the implementation and execution of public health policy through court decisions that impose the acquisition of health services, with the possibility of compromising the systematic programming of the Public Health Policy through the System Health Service (SUS). In this context, the problems with the judicialization of health is an important way of accessing public health services, but it can mean serious risks to the systematic and planning of meeting collective needs. Objective: To analyze the costs of legalization of health in the State of Acre, Western Amazon, Brazil. Method: Cross-sectional descriptive and documentary study, with secondary data obtained from the Public Budget Information System in Health (SIOPS), Budget, Financial and Accounting Administration System (SAFIRA), from the Health Department of Acre and from legal proceedings obtained on the website of the Court of Justice of the State of Acre (TJ/AC), from 2010 to 2016. Results: The costs of the judicialization of health in the State of Acre, from 2014 to 2017, were greater than $R \$ 10.5$ million reais distributed between medicines (53.16\%) and medical/hospital material $(0.49 \%)$. It is worth mentioning the weakness of accounting records corresponding to 4.8 million reais (46.35\%) of the resources applied with judicialization, and represent $0.31 \%$ of the resources invested in health in the same period in the State of Acre. Conclusion: The cost of judicialization of health in the State of Acre exists and is not properly provided for in the budget and financial planning, compromising the systematic expenditure of Public Policy on Health.

Keywords: Public Health Policies. Health Cost. Health Judicialization. 


\section{INTRODUÇÃO}

O direito à saúde é salvaguardado pela Constituição Federal em aspecto individuais e coletivos, cabendo ao Estado, por meio de política pública de saúde e, operacionalizado pelo Sistema Único de Saúde (SUS) (BRASIL, 1998). Em função dos anseios de uma sociedade que lutava por direitos e deveres com uma forma mais justa e igual, que resultou na criação do Sistema Único de Saúde Brasileiro (TOLEDO, 2013).

Há toda uma sistemática de financiamento do SUS por meio da Lei Complementar (LC) № 141 a qual dispõe sobre valores mínimos do custeio que deve ser executada pela União e pelos Estados seguida pelas normas de fiscalização Brasil (2000), como a efetivação da Emenda Constitucional (EC) ㄲo 29 assim, desta forma garantindo os recursos necessários para o financiamento das ações e serviços públicos de saúde e contribuindo para a diminuição das desigualdades horizontais nos recursos aplicados pelos municípios no financiamento da saúde pública (BRASIL, 2014; VAZQUEZ, 2011).

As ações e os serviços de saúde públicos formam uma rede regional e hierarquizada no SUS, que possibilitam a execução da política de saúde no âmbito do governo Federal, Estadual e Municipal, com base nos princípios da universalidade e integralidade, nos termos da Constituição e das Leis Federal $n^{\circ}$ 8.080/90 e 8.142/1990 (BRASIL, 2011).

Diante da abrangência e complexidade da execução da política pública de saúde, a Judicialização da Saúde se dá por vários fatores entre eles a causa do crescimento da população, o aumento da expectativa de vida, a forte desigualdade social que marca nosso país, impedindo o acesso da maior parte da população a serviços de saúde de qualidade, e a maior acessibilidade da população ao Poder Judiciário brasileiro por meio dos juizados especiais e outros.

Neste contexto, os problemas com a judicialização da saúde é uma importate via de acesso aos serviços em saúde pública, mas pode significar sérios riscos a 
sistemática e planejamento ao atendimento das necessidades coletivas (BARROSO, 2010).

No âmbito da saúde brasileira, vários estudos destacam os altos custos na aquisição de medicamentos sendo esses muitas vezes, monopólio de algumas indústrias farmacêutas trazendo consigo valores exorbitantes e que ferem a sistemática de funcionamento do SUS ao comprometerem a integralidade e a universalidade do atendimento público (BARROSO, 2010).

Os valores elevados com as demandas judicializadas em saúde correspondente ao ano de 2009 , no Brasil, são equivalente ao valor total de $\mathrm{R} \$$ 41,40 bilhões de reais, e os impactos desses valores são prejudiciais sobre a política de atendimento em saúde como um todo. Isso se dá porque os serviços em saúde são minorados à população em face do atendimento individualizado de outros poucos indivíduos (BRASIL, 2011).

Diante do exposto, este estudo objetiva analisar os custos da judicialização da saúde no Estado do Acre, identificando a necessidade e a contibuição para a melhoria do atendimento ao cidadão e a implementação de políticas públicas.

\section{MÉTODO}

Trata-se de um estudo com abordagem quantitativa, transversal, de caráter descritivo (GIL et al., 2002), com levantamento de dados secundários extraídos do Sistema de Informação Orçamentária Pública em Saúde (SIOPS) do Sistema de Administração Orçamentária, Financeira e Contábil (SAFIRA) e em Acórdãos com trânsito em julgado no Tribunal de Justiça do Estado do Acre (TJ/AC), Amazônia Ocidental - Brasil (Figura 1), no período de 2010 a 2017.

Destaca-se que os dados extraídos dos sistemas SIOPS e do SAFIRA compreenderam ao período de 2014 a 2017, tendo em vista que somente a partir do ano de 2014 os dados foram adequadamente escriturados na Secretaria de Estado de Saúde (SESACRE). No período anterior a 2014, os custos em judicialização eram escriturados como despesas normais e não decorrentes de imposição judicial. 
À coleta do banco de dados foi obtida no Tribunal de Justiça do Estado do Acre (TJ/AC), no período de 2010 a 2017, disponível online no Portal de Serviço do Sistema de Automação-(e-SAJ), desenvolvido para facilitar a troca de informações e agilizar o tramite processual entre advogados, cidadãos e serventuários da justiça.

Como um serviço público, encontra-se disponível em: http://esaj.tjac.jus.br/cjsg/resultadoCompleta.do, e de uso de termos específicos por assuntos como: Saúde - 10069 Tratamento Médico-Hospitalar e/ou Fornecimento de Medicamentos; Órgão Julgador: Termo Tribunal Pleno Jurisdicional; Origem: $2^{2}$ Grau; Tipo de Decisão: Acórdão e Ordenar por data de registro, o qual permitiu a identificação de 47 acórdãos.

Em seguida, utilizou-se os descritores: Políticas de Saúde Pública, Custo em Saúde, Judicialização da Saúde, permitindo identificar 44 Acórdãos na base de dados para melhor relacionarmos com a revisão de literatura. Foi utilizado ainda o critério de inclusão de acórdãos (decisões judiciais colegiadas) emitidos pelo Tribunal Pleno Jurisdicional do Tribunal de Justiça do Estado do Acre e que expressaram os valores nominais impostos por acórdãos em matéria de tratamento médico hospitalar e/ou fornecimento de medicamentos, cuja discussão não mais se admita naquela instância.

Foram excluídas da amostra 17 acórdãos por estarem relacionado as decisões monocráticas, agravo regimental e embargos à execução, que não apresentaram valores nominais e anteriores a 2010. Assim, chegou-se ao resultado final de 19 acórdãos emitido em Mandados de Segurança (MS), possibilitando, portanto, a análise por meio da aplicação de procedimento sistemático e objetivo para escrever o conteúdo das amostras, com a finalidade de entender e avaliar as informações contidas no material de estudo.

As etapas de filtragem deste processo de aplicação dos critérios de inclusão e exclusão estão descritas na Figura 1. 


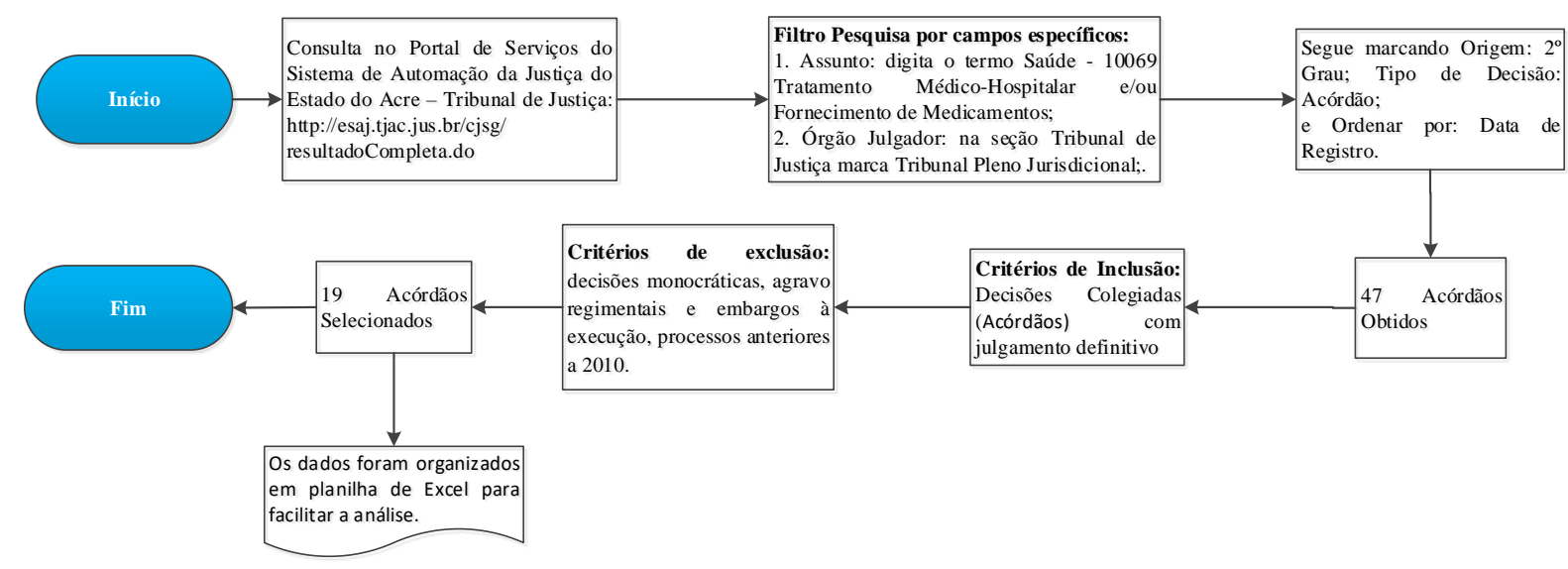

Figura 1 - Fluxograma dos procedimentos metodológicos de seleção de amostra com Acórdãos do TJ/AC, no período de 2010 a 2017.

Para auxiliar na complementação do suporte teórico, foi realizada uma revisão bibliográfica pesquisada em bases de dados da área de Saúde como Bireme, Web of Science e Lilacs, tendo como base os principais conceitos que circulam o tema do direito à saúde e a Judicialização desse direito.

Nesse intuito, as ações constitucionais do MS que tem como partes envolvidas Impetrante, que é o cidadão ou empresa que se utiliza da ação para defesa de direitos e impetrado que é a autoridade dita coatora porque em primeiro momento nega-se o direito buscado em juízo. É ação impetrada em juízo, e possui rito especial de tramitação por não admitir produção de prova em audiência, para proteção de direito líquido e certo.

Por conseguinte, direito líquido e certo é o direito de prova pré-constituída, não havendo necessidade de dilação probatória para demonstração de sua validade e legitimidade em juízo a fim de ser gozada pelo beneficiário da decisão judicial. Trata-se de direito manifesto na sua existência, delimitado na sua extensão e apto a ser exercitado no momento da impetração (LENZA, 2012).

Considerou-se os critérios de inclusão que são os Acórdãos (decisões judiciais colegiadas) exarados pelo Tribunal Pleno Jurisdicional do Tribunal de Justiça do Estado do Acre e que expressam os valores nominais impostos por 
Acórdãos em matéria de tratamento médico hospitalar e/ou fornecimento de medicamentos, cuja discussão não mais se admita naquela instância.

O Tribunal Pleno Jurisdicional tem a competência para processamento e julgamento, em única e última instância, de mandados de segurança quando a autoridade coatora possuir status de Secretário de Estado, auxiliar direto do Chefe do Poder Executivo (Governador), nos termos do art. 10, inciso I, alínea "c", da Lei Complementar Estadual no 221, de 30 de dezembro de 2010 (BRASIL, 2010). Única instância, no caso, que significa que não há outro órgão de julgamento para essas ações e última instância que depois de emitida decisão, não mais é possível a discussão da questão julgada no ambito do Estado do Acre.

Foram excluidos as decisões monocráticas, agravo regimental e embargos à execução, que não apresentaram valores nominais e anteriores a 2010. Decisões monocráticas são decisões proferidas por único magistrado (MACEDO; VIAFORE, 2018). Contrapõe-se às decisões colegiadas, típicas de casos em que o pedido jurisdicional esteja em fase de recurso, no caso, do TJ/AC. Agravo Regimental são recursos propostos sobre decisões colegiadas e que tem o fim de revisão a decisão quando o julgamento é por maioria de votos, ou seja, metade mais um. São recursos com previsão legal nas Leis Orgânicas de cada Tribunal de Justiça de Estado e nas unidades federativas e no caso do Acre, é a Lei Complementar Estadual no 221, de 30 de dezembro de 2010 (BRASIL, 2010).

Os Acórdãos em Agravos Regimentais foram excluídos por significar replicações de temas e fatos já tratados nos Acórdãos selecionados. E, também foram excluídos recursos de Embargos de Declaração que constituem recursos interpostos para o fim de corrigir omissão, obscuridade e contradição, no caso, em Acórdãos do TJ/AC, sendo excluídos por também significarem duplicação de discussão de fato e direito dos Acórdãos selecionados (MACEDO; VIAFORE, 2018).

De igual modo foram excluídos os Acórdãos que apresentavam alguma inconsistência de inclusão no e-SAJ, como: erro ou ausência de numeração de autuação e cujas demandas foram autuadas anteriores a 2010.

Por fim, os dados foram organizados em categorias e, em seguida, foram apresentados em tabelas de acordo com organização feita no pacote Microsoft Office Excel 2016. 
Sendo esta pesquisa, realizada segundo a Resolução 466/2012 do Conselho Nacional de Saúde e foi aprovada pelo Comitê de Ética em Pesquisa da Faculdade de Juazeiro do Norte (FJN), através do Parecer de Aprovação nํ 1.802.271.

\section{RESULTADOS}

Os custos totais em saúde registrados no Sistema de Informação Orçamentária Pública em Saúde (SIOPS) foram acima de $R$ \$ 3,4 bilhões de reais, e os gastos totais com a judicialização em saúde, foram um pouco acima de $R \$ 10,5$ milhões, conforme Tabela 1.

Os recursos financeiros aplicados em saúde no período foram superiores aos exigidos em Li (12\%), com variação entre os percentuais de 14,24\% (2016) a $17,32 \%$ (2014), ao passo que os custos da judicialização variaram no mesmo período de 0,16\% a 0,43\%, considerando as despesas totais em saúde por ano respectivo.

Tabela 1 - Custo da Judicialização no Acre no período de 2014 a 2017, em face aos investimentos em Saúde.

\begin{tabular}{ccccc}
\hline PERÍODOS & SIOSP $(\mathbf{R} \$)$ & $\%$ & SESACRE $(\mathbf{R} \mathbf{)})$ & $\%$ \\
\hline 2014 & $854.941 .985,63$ & 17,32 & $3.301 .611,66$ & 0,39 \\
2015 & $837.773 .665,82$ & 15,37 & $3.592 .129,83$ & 0,43 \\
2016 & $838.603 .970,43$ & 14,24 & $2.261 .828,66$ & 0,27 \\
2017 & $881.087 .024,50$ & 15,04 & $1.408 .729,01$ & 0,16 \\
TOTAL (R\$) & $\mathbf{3 . 4 1 2 . 4 0 6 . 6 4 6 , 3 8}$ & - & $\mathbf{1 0 . 5 6 4 . 2 9 9 , 1 6}$ & -
\end{tabular}

Fonte: Elaborada pelo autor em pesquisa documental (2018), SIOSP: Sistema Informação Orçamentária Pública em Saúde (DATASUS), SESACRE: Secretaria de Estado de Saúde do Acre.

Os custos da judicialização em saúde por subfunção são representados na Tabela 2, descrevendo-se um valor acima de $R \$ 10,5$ milhões de reais distribuídos 
entre medicamentos $(53,16 \%)$ e material médico/hospitalar $(0,49 \%)$ como os mais elevados.

Tabela 2 - Custo da Judicialização em saúde por natureza de despesas em saúde em face dos gastos totais no período de 2014 a 2017.

\begin{tabular}{lccccccc}
\hline SAFIRA (R\$) & Período & $\begin{array}{c}\text { Medicamentos } \\
\mathbf{( R \$ )}\end{array}$ & $\%$ & $\begin{array}{c}\text { Material } \\
\text { médico/hospitalar } \\
\mathbf{( R \$ )}\end{array}$ & $\%$ & $\begin{array}{c}\text { Outros } \\
\text { Serviços não } \\
\text { especificados }\end{array}$ & $\%$ \\
\hline $\mathbf{1 0 . 5 6 4 . 2 9 9 , 1 6}$ & 2014 & $1.116 .359,01$ & & $18.963,90$ & & & \\
& 2015 & $1.473 .677,24$ & & - & & & \\
& 2016 & $1.851 .421,42$ & & $2.127,80$ & & & \\
& 2017 & $1.174 .676,75$ & & $31.031,71$ & & & \\
TOTAL (R\$) & & $\mathbf{5 . 6 1 6 . 1 3 4 , 4 2}$ & 53,16 & $\mathbf{5 2 . 1 2 3 , 4 1}$ & 0,49 & $\mathbf{4 . 8 9 6 . 0 4 1 , 3 3}$ & 46,35 \\
\hline
\end{tabular}

Fonte: Elaborada pelo autor em pesquisa documental (2018), SIOPS: Sistema Informação Orçamentária Pública em Saúde (DATASUS), SESACRE: Secretaria de Estado de Saúde do Acre.

Na Tabela 3 descrevem-se os valores decorrentes da judicialização em saúde no Estado do Acre no período de 2010 a 2017, somando o valor acima de $R \$ 245$ mil reais, que correspondem em $52,78 \%$ das demandas ajuizadas sem projeção anual para os casos de doenças crônicas.

Os serviços pleiteados predominantemente foram medicamentos (83,33\%), seguidos de serviços e exames diversos (16,67\%).

Tabela 3 - Demandas em saúde ajuizadas no Tribunal de Justiça do Estado do Acre estratificado por ano, diagnóstico, prescrição médica e valor nominal expressos, no período de 2010 a 2017.

\begin{tabular}{cccc}
\hline $\begin{array}{c}\text { Acórdão } \\
\text { Ano }\end{array}$ & Diagnósticos & Prescrição Médica & Valor (R\$) \\
\hline $6977 / 2013$ & Trombofilia & Clexane 40 mg & $5.734,80$ \\
$7204 / 2013$ & $\begin{array}{c}\text { Insuficiência respiratória } \\
\text { 30 Grau e Doença } \\
\text { Pulmonar Crônica }\end{array}$ & Spiriva Respimat 2,5 mg & 274,57 \\
& Alfapeginterferona 2B 180 & \\
$7083 / 2013$ & Hepatite C, Crônica & $\begin{array}{c}\text { mcg-ampola, Ribavirina } \\
\text { 250 mg-capsula e }\end{array}$ & $35.000,00$ \\
$7066 / 2013$ & Hepatite C Genótipo I & Boceprevir 200 mg & \\
& & Telaprevir 375 mg & $62.107,92$ \\
\hline
\end{tabular}




\begin{tabular}{|c|c|c|c|}
\hline $7179 / 2013$ & $\begin{array}{l}\text { Doença Pulmonar } \\
\text { Obstrutiva crônica, tipo } \\
\text { enfisema, classe IV }\end{array}$ & $\begin{array}{l}\text { Inibidor de Protease } \\
\text { Victrelis (Boceprevir } \\
200 \mathrm{mg} \text { ) }\end{array}$ & $10.000,00$ \\
\hline $7596 / 2014$ & Cirrose & $\begin{array}{c}\text { Entecavir 0,5 mg } \\
\text { Interferon Peguilado } 180\end{array}$ & $3.049,00$ \\
\hline $7293 / 2014$ & Hepatite C, Crônica & $\begin{array}{c}\text { mg, Ribarivina } 250 \text { mg - } \\
\text { Cápsula e Telaprevir } 375 \\
\text { mg }\end{array}$ & $30.000,00$ \\
\hline $7510 / 2014$ & $\begin{array}{l}\text { Osteoporose com fraturas } \\
\text { vertebrais e punho }\end{array}$ & Teriparatida $250 \mathrm{mg}$ & $6.900,00$ \\
\hline $7482 / 2014$ & $\begin{array}{c}\text { Hepatite C, Crônica Viral } \\
\text { B }\end{array}$ & Entecavir $0,5 \mathrm{mg}$ & $2.870,00$ \\
\hline $8161 / 2014$ & Câncer na Vesícula Biliar & Sandostain LAR-20 IM & $4.000,00$ \\
\hline $7466 / 2014$ & $\begin{array}{l}\text { Lesão por esforço } \\
\text { repetitivo - LER }\end{array}$ & $\begin{array}{l}\text { Eletroneuromiografia } \\
\text { MMSS e MMII }\end{array}$ & 900,00 \\
\hline $7427 / 2014$ & $\begin{array}{c}\text { Histórico de Trombofilia } \\
\text { Hereditária }\end{array}$ & Enoxapirina 40 mg & $3.800,00$ \\
\hline $7431 / 2014$ & Adenoide e Extra-Sistoles & $\begin{array}{l}\text { Holter } 24 \text { horas e } \\
\text { Videoendoscopia } \\
\text { Nasossinusal }\end{array}$ & $3.000,00$ \\
\hline & Microcefalia & TFD - Exame Exoma & \\
\hline & Transtorno Mental & $\begin{array}{l}\text { Rispiridona 1mg } \\
\text { Imipramina 75mg }\end{array}$ & $\begin{array}{l}68,00 \\
75,00\end{array}$ \\
\hline $8708 / 2015$ & $\begin{array}{c}\text { Osteoporose lombar } \\
\text { grave com risco de fratura } \\
\text { patológica }\end{array}$ & $\begin{array}{c}\text { Teriparatida Fortéo } 250 \\
\text { MCG }\end{array}$ & $11.559,50$ \\
\hline $8225 / 2015$ & Hepatite C, Crônica & $\begin{array}{c}\text { Alfapeginterferona 2B } 180 \\
\text { mcg-ampola, Ribavirina } \\
250 \mathrm{mg} \text {-capsula e } \\
\text { Boceprevir } 200 \mathrm{mg}\end{array}$ & $35.000,00$ \\
\hline $6977 / 2013$ & $\begin{array}{c}\text { Hepatite B e Insufiência } \\
\text { Renal }\end{array}$ & Entecavir 0,5 mg & $12.000,00$ \\
\hline $7204 / 2013$ & $\begin{array}{c}\text { Encefalopatia Crônica não } \\
\text { evolutiva }\end{array}$ & Genético CGH-Array & $6.300,00$ \\
\hline \multicolumn{3}{|c|}{ Valor de alçada das demandas } & $245.438,79$ \\
\hline
\end{tabular}

Fonte: Produzida pelo autor com base em análise da jurisprudência do Tribunal de Justiça-AC.

\section{DISCUSSÃO}

Os custos da judicialização em saúde no Estado do Acre, no período de 2014 a 2017 , representaram $0,31 \%$ dos recursos investidos em saúde no mesmo período, 
considerando os demonstrativos do SIOPS, destacando que o Estado do Acre sempre investiu em valores nominais acima do percentual exigido em Lei (12\%), portanto, afastando-se toda e qualquer possibilidade de aplicação de sanções (CAMPELLI; CALCO, 2007).

Os percentuais registrados na pesquisa entre $14,24 \%$ a $17,32 \%$ (Tabela 1) denotam os esforços do Estado para o cumprimento da legislação em vigor, não obstante, o percentual de $0,31 \%$ da judicialização da saúde em face dos recursos aplicados pode ser considerado proporcionalmente, elevados quando comparados a outros Estado (MEDEIROS; DINIZ; DOEDERLEIN SCHWARTZ, 2013). Outro fator relevante nos achados da pesquisa (Tabela 1) é que os gastos utilizados com a judicialização na SESACRE, ocorreu redução de $0,36 \%$ a $0,16 \%$ entre os anos de 2014 a 2017.

Apesar de se considerar elevados os custos com a judicialização em saúde no período de estudo, as aplicações em saúde sofreram elevação mínima de 2,97\% ao passo que pode se evidenciar uma redução de $42,67 \%$ nas demandas judiciais em saúde no mesmo período (Tabela 1).

A judicialização em saúde no período de 2014 a 2017 compreendeu o valor total de $R \$ 10.564 .299,16$ (dez milhões, quinhentos e sessenta e quatro mil, duzentos e noventa e nove reais e dezesseis centavos), com medicamentos $(53,16 \%)$, material médico/hospitalar $(0,49 \%)$, e outros serviços não devidamente especificados e sistematizados contabilmente (46,35\%) (Tabela 2).

Os gastos com as demandas da judicialização em saúde corroboram com outros estudos já realizados, onde predomina o maior índice de solicitação os serviços de saúde e não medicamentos (POLI; RAMOS, 2013; MACHADO et al., 2011; DINIZ; MACHADO; PENALVA, 2014).

Os registros do SAFIRA de $46,35 \%$ em rubricas não sistematizadas quanto às despesas judicializadas em saúde, representou inconsistências significativas relativo à identificação do objeto da despesa aplicadas em judicialização da saúde, prejudicando a melhor tomada de decisão de seus gestores, no tocante a resolutividade destas demandas.

Um fator importante também que não é vislumbrado nos dados do SIOPS e SESCRE diz respeito a solidariedade entre os entes federados (União, Estados e 
Municípios). Destaca-se a maior parte das demandas judicializadas por medicamentos sempre são suportadas pelo orçamento do Estado (MACHADO; PENALVA, 2014), não havendo qualquer critério razoável para a distribuição das responsabilidades significando do ponto de vista orçamentário, um entrave a execução e desperdício da política pública de saúde (GOMES et al., 2014).

Os processos judicializados no período de 2010 a 2017, considerando as demandas transitadas em julgado e que apresentaram valores nominais destas, expressaram o montante de $\mathrm{R} \$ 245.438,79$ (duzentos e quarenta e cinco mil, quatrocentos e trinta e oito reais e setenta e nove centavos), com maior recorrência nos casos de Hepatite $C$ (Tabela 3 ).

Os tratamentos com Hepatite $C$ são os mais elevados no que se diz respeito aos custos, porém, se considerarmos uma projeção anual os gastos poderão ultrapassar um 12 avos. Contudo, a ausência de planejamento e a decisão equivocada pode agravar ainda mais os desperdícios com o erário. Cita-se como exemplo, a inclusão de novas drogas para o tratamento de Hepatite C, como sofosbuvir e semeprevir autorizados pelo Ministério da Saúde (MS), que possui uma taxa de cura de $98 \%$ dos casos, mas, quando aplicados conjuntamente o tratamento pode chegar até 328 mil reais (ISTO É, ed. 2520, 2017).

Os valores expressos nos processos podem se elevarem consideravelmente nos casos de doenças crônicas e nos casos em que os tratamentos são realizados fora de domicílio (TFD) e, principalmente quando incluso nesses montantes os custos indiretos da judicialização em saúde, como despesas com acompanhante, hospedagem, alimentação, passagens aéreas e outras despesas necessárias ao bem-estar dos demandados. Segundo a agência de notícias do Acre, foram gastos mais de 12,4 milhões com TFD, independentemente de judicialização (SECOM ACRE, 2018).

Com relação a uma avaliação crítica da própria pesquisa, em especial, das limitações, observou-se a ausência dos dados secundários atualizados pela unidade gestora, ou seja, a sistemática da padronização destes são inconsistentes, visto que não apresentam várias rubricas sobrepostas em alguns casos e com fragmentadas em outras, como por exemplo, quando comparamos as ações transitadas e julgadas com as decisões judiciais. 
Percebeu-se que a aplicações de recursos financeiros para a saúde pública atendeu os limites legais, não obstante, se destaca a necessidade de melhor planejamento de custo em saúde, considerando a especificidade de casa serviço prestados, em face das necessidades da coletividade, para o fim de evitar sobreposição de ações dos entes federados e prejuízos na aquisição de medicamentos e outros bens de saúde.

Dessa forma, o custo da judicialização em saúde no Estado do Acre no período de 2014 a 2017 atendeu aos limites legais.

\section{CONCLUSÃO}

O custo da judicialização da saúde no Estado do Acre existe e não é devidamente aprovisionado no planejamento orçamentário e financeiro, portanto, compromete a sistemática de gastos da Política Pública em Saúde.

Por fim, considerando a natureza e o conteúdo das demandas e seus interessados, a judicialização da saúde torna-se o meio de acesso aos serviços de saúde básicos a população que necessita e apresenta baixo recursos financeiros para o cuidado à saúde.

Os resultados deste estudo demonstraram que é possível uma maior eficiência e atuação do Poder Executivo na resolução dos casos que se repetem na justiça por judicialização da saúde no Estado de Acre. É, portanto, necessárias intervenções de gestão para atualização e inserção de novos medicamentos no protocolo do SUS, e assim melhorar os resultados de atendimentos humanizado à saúde na atenção básica garantidos na Constituição Brasileira. 


\section{REFERÊNCIAS BIBLIOGRÁFICAS}

BARROSO, Luís Roberto. Da falta de efetividade à judicialização excessiva: direito à saúde, fornecimento gratuito de medicamentos e parâmetros para a atuação judicial. 2. tir. Rio de Janeiro: Lumen Juris, 2010. p. 875-903.

BRASIL, Ministério da Saúde. Secretaria de Gestão Estratégica e Participativa. Regulamentação da Lei $\mathbf{8 . 0 8 0}$ para fortalecimento do Sistema Único da Saúde: decreto 7508, de 2011.

BRASIL. Constituição (1988). Constituição da República Federativa do Brasil. Artigo 198. Brasília: Senado Federal; 1988.

BRASIL. ESTADO DO ACRE. Lei Complementar Estadual no 221, de 30 de dezembro de 2010. Dispõe sobre o Código de Organização e Divisão Judiciárias do Estado do Acre e dá outras providências.

BRASIL. Lei no 101, de 4 de maio de 2000. "Estabelece normas de finanças públicas voltadas para a responsabilidade na gestão fiscal e dá outras providências.". Disponível em: <http://www.planalto. gov.br/ccivil_03/leis/lcp/lcp101.htm>. Acesso em: 11 jan. 2014.

CAMPELLI, Magali Geovana Ramlow; CALVO, Maria Cristina M. O cumprimento da Emenda Constitucional nํ. 29 no Brasil. Cadernos de Saúde Pública, v. 23, p. 1613-1623, 2007.

DINIZ, Debora; MACHADO, Teresa Robichez de Carvalho; PENALVA, Janaina. A judicialização da saúde no Distrito Federal, Brasil. Ciência \& Saúde Coletiva, v. 19, p. 591-598, 2014.

GIL, Antonio Carlos et al. Como elaborar projetos de pesquisa. São Paulo: Atlas, 2002.

GOMES, Dalila F. et al. Judicialização da saúde e a audiência pública convocada pelo Supremo Tribunal Federal em 2009: o que mudou de lá para cá? Saúde em Debate, v. 38, n. 100, p. 139156, 2014.

ISTO É. O preço da cura da Hepatite C. 2017. Disponível em: <https://istoe.com.br/357467_O+PRECO+DA+CURA+DA+HEPATITE+C/>. Acesso em: 13 abr. 2018.

LENZA, Pedro. Direito constitucional esquematizado. Editora Saraiva, 2012.

MACEDO, Elaine Harzheim; VIAFORE, Daniele. A decisão monocrática e a numerosidade no processo civil brasileiro. Livraria do Advogado Editora, 2018.

MACHADO, Marina Amaral de Ávila et al. Judicialização do acesso a medicamentos no Estado de Minas Gerais, Brasil. Revista de Saúde Pública, v. 45, p. 590-598, 2011.

MEDEIROS, Marcelo; DINIZ, Debora; DOEDERLEIN SCHWARTZ, Ida Vanessa. A tese da judicialização da saúde pelas elites: os medicamentos para mucopolissacaridose. Ciência \& Saúde Coletiva, v. 18, n. 4, 2013.

POLI, Gustavo Luiz; RAMOS, Flávio. Apontamentos acerca da judicialização da política no brasil. Revista Eletrônica Direito e Política, v. 8, n. 1, p. 719-744, 2013.

SECOM ACRE. Governo do Acre investiu mais de R\$ 12 milhões em TFD ao longo de 2017. 2018. Disponível em: <https://agencia.ac.gov.br/governo-do-acre-investiu-mais-de-r-12-milhoesem-tfd-ao-longo-de-2017/>. Acesso em: 13 abr. 2018. 
TOLEDO, Luciano Medeiros. (Org.) Movimentos sociais e saúde. Organizado por Luciano Medeiros de Toledo e Paulo Chagastelles Sabroza. Rio de Janeiro, ENSP/FIOCRUZ, 2013.

VAZQUEZ, Daniel Arias. Efeitos da regulação federal sobre o financiamento da saúde. Cadernos de Saúde Pública, v. 27, p. 1201-1212, 2011. 